\title{
O VILANCETE NO CANCIONEIRO GERAL DE GARCIA DE RESENDE: TRADIÇÃO E INOVAÇÃO*
}

\section{THE VILANCETE IN GARCIA DE RESENDE'S CANCIONEIRO GERAL: TRADITION AND INOVATION}

\author{
Geraldo Augusto Fernandes \\ Universidade Federal do Ceará
}

\begin{abstract}
Resumo: No Cancioneiro Geral de Garcia de Resende, a forma fixa "vilancete" aparece em 76 poemas. A característica formal do vilancete é conter dois ou três versos como mote, seguido de uma glosa de uma ou mais estrofes de sete versos. No entanto, em muitos vilancetes, alguns analisados neste estudo, nota-se que a procura central é a de inovação e de adequação dos novos temas a formas já consagradas. Para isso, os poetas palacianos desconstruíram a estrutura tradicional da glosa. Essa fuga dos conceitos tradicionais da estrutura do vilancete confirma outra característica do
\end{abstract} Cancioneiro: a irregularidade que, para muitos críticos, é sinal de inovação. Dessa forma este artigo analisa como os poetas palacianos dos Quatrocentos e Quinhentos fizeram uma releitura do vilancete, inovando-o e adaptando-o aos novos tempos. Para confirmar isso, pretende-se apresentar exemplos e análise de alguns vilancetes presentes na Compilação de Garcia de Resende.

Palavras-chave: Cancioneiro Geral de Garcia de Resende, Poesia Palaciana, Formas Fixas
Abstract: In Garcia de Resende's Cancioneiro Geral, the fixed form "vilancete" appears in 76 poems. The formal characteristic of the vilancete is to have two or three verses called motto, followed by a gloss of one or more stanzas of seven verses. However, in many vilancetes, some analyzed in this article, it is observed that the aims of the courtly poets were the search for innovation and adaptation of new themes to a traditional form. To achieve this aim, they "deconstruct" the traditional structure of the gloss. This escape from the traditional concepts of the vilancete confirms another characteristic of Garcia de Resende's song book: the irregularity, which for many scholars is a sign of innovation. This article aims to present how the courtly poets of the Fourteenth and Fifteenth centuries developed this traditional form, combining it with contemporary and traditional themes. In order to confirm this innovation, examples taken from Resende's Cancioneiro will be shown and analyzed.

Keywords: Cancioneiro Geral de Garcia de Resende, Courtly Poetry, Fixed Forms

\footnotetext{
* Este texto é uma extensão da seção dedicada aos vilancetes do Cancioneiro Geral de Garcia de Resende, que apresentei em minha tese de doutoramento. Cf. FERNANDES, Geraldo Augusto. $O$ amor pela forma no Cancioneiro Geral de Garcia de Resende. 402p. Tese de Doutorado. (Literatura Portuguesa). 2011. Faculdade de Filosofia, Letras e Ciências Humanas, Universidade de São Paulo, São Paulo, 2011. A Tese completa pode ser acessada online no seguinte endereço: http://www.teses.usp.br/teses/disponiveis/8/8150/tde-15092011-130549/.
} 
Dos 880 poemas compilados por Garcia de Resende entre 1449 e 1516, editados no seu Cancioneiro Geral em 1516, 76 apresentam-se sob a forma de vilancete. Pertencentes ao que se denomina "forma fixa", a característica estrutural do vilancete (do castelhano "villancico", vilão) é conter dois ou três versos como mote, e esses versos podem ser do próprio autor, de autor alheio ou mesmo anônimo; pode ser também composto por ditos populares ou máximas e provérbios, glosados em uma ou mais estrofes de sete versos (sétima). Contudo, na Compilação de Resende encontramse poemas cuja glosa se estende para oito, nove e mesmo dez versos, caracterizando inovações e fugas da conceituação tradicional. Essas inovações e fugas são próprias dos poetas palacianos portugueses, como se atesta, por exemplo, nos vilancetes. Mas não só nessa forma poemática - nas outras cinco formas cultivadas pelos palacianos o que se atesta é a procura pela inovação; observe-se isso nas cantigas, nas trovas, nas esparsas, nas baladas e principalmente nos poemas de formas mistas - esses, a grande inovação do Cancioneiro resendiano.

É proposta deste artigo, então, apresentar e analisar o que é tradicional e o que é inovador nos vilancetes compilados por Resende. Inicio a análise mostrando suas origens e conceituações para, em seguida, apresentar as inovações.

Para Le Gentil, o "villancico", nome castelhano do vilancete, é um gênero essencialmente popular e o

villancico du XVe. siècle est un genre raffiné, qui releve, chez les poetes qui le cultivent, des préocupations artistiques et érudites. Le villancico a d'abord été un pastiche littéraire; il chantait, interprèté, stylisé, quelques thèmes de la chanson de danse primitive; mais, dans les milieux courtois, il ne pouvait manquer de se confondre peu à peu avec la chanson d'amour et, en fait, il ne s'en distingue biêntot plus parfois ni par le ton, ni par le contenu ${ }^{1}$.

Ainda para o estudioso, a glosa - característica de vilancetes e cantigas medievais adquire importância de destaque na literatura peninsular do fim do século $\mathrm{XV}$, o que se estende para o Renascimento e mesmo posteriormente. Este gosto por glosar é bem medieval e próprio do pensamento escolástico, pois na glosa se cultivam hábitos dedutivos. Porém, esse gosto fazia parte do costume europeu, não só peninsular, o que revela a mentalidade do homem medieval. Para Le Gentil, na verdade, glosar caracteriza-

\footnotetext{
${ }^{1}$ LE GENTIL, Pierre. La poésie lyrique espagnole et portugaise à la fin du Moyen âge: les thèmes, les genres et les formes. 2 vol. Rennes: Plihon, 1949-52, p. 261.
} 
se por certo respeito religioso ${ }^{2}$. Margarida Vieira Mendes, num estudo sobre o primeiro dos poemas apresentados na Compilação de Garcia de Resende, o "Cuidar e sospirar", referindo-se à citação, diz que "equivale à argumentação pela autoridade, [e] serve também para revelar a destreza ou habilidade específica dos trovadores, a sua arte da memória e do 'insert' versificatório equivalente às 'glosas' que proliferam no Cancioneiro geral, o que é um traço característico de arte poética de $1500^{3}$." O que se percebe no $C G G R^{4}$ é que a glosa apresenta não só apreço e veneração pelos autores antigos, mas também pelos vizinhos - no caso dos portugueses, pelos castelhanos contemporâneos.

No Tratado da Imitação, Livro I, capítulo III, Dionísio de Halicarnasso referese à diferença entre "imitação" e "emulação"; o primeiro termo seria uma atividade que refunde um modelo, a partir de certos princípios teóricos, e o segundo seria "uma actividade do espírito que o move no sentido da admiração daquilo que lhe parece ser belo 5 ". Mais à frente, diz que

a imitação não é a utilização dos pensamentos, mas sim o tratamento, como arte, semelhante ao dos antigos. E imita Demóstenes não aquele que diz o mesmo que Demóstenes, mas sim o que diz à maneira de Demóstenes. E o mesmo se diga quanto a Platão e a Homero. Toda a imitação se resume nisto: emulação da arte que refunde a semelhança dos pensamentos ${ }^{6}$.

O mesmo ponto de vista defende o autor de Retórica a Herênio, no Livro IV, quando questiona: "não é a própria autoridade dos antigos que torna as coisas mais prováveis e os homens mais dispostos a imitá-los?", $\mathrm{O}$ autor defende que "nisto reside a maior arte:

\footnotetext{
${ }^{2}$ LE GENTIL, 1952, p. 296-297.

${ }^{3}$ CUIDAR e Sospirar (1483), O. Fixação do texto, introdução e notas de Margarida Vieira Mendes. Lisboa: Comissão Nacional para as Comemorações dos Descobrimentos Portugueses, 1997. (Colecção Outras Margens, Série Poesia do Tempo dos Descobrimentos), p. 29.

${ }^{4}$ A sigla $C G G R$ refere-se ao Cancioneiro de Resende, objeto deste artigo. A referência bibliográfica para os poemas do CGGR é: CANCIONEIRO Geral de Garcia de Resende. Fixação do texto e estudo por Aida Fernanda Dias. Maia: Imprensa Nacional-Casa da Moeda, 1990-1993. Volumes I a IV. Os poemas citados neste artigo e não reproduzidos podem ser consultados nesta mais recente edição de Aida Fernanda Dias.

${ }^{5}$ DIONÍSIO DE HALICARNASSO. Tratado da imitação. Ed. Raul M. R. Fernandes. Lisboa: Instituto Nacional de Investigação Científica. [1986], p. 45-69, Livros Primeiro, Segundo e Terceiro, p. 46. João Adolfo Hansen, valendo-se do que escreveu o seiscentista Emanuele Tesauro, diz que "a emulação é a imitação que supera o modelo imitado" e ela "visa a produzir, por outros modos e por outros meios, um prazer semelhante ou superior à obra imitada. Para isso, pretende produzir agudezas mais agudas que as da obra imitada". Mais à frente, conclui que "o modo de produzir semelhanças e diferenças agudas distingue emulação de imitação servil". (HANSEN, João Adolfo. Retórica da Agudeza. Letras Clássicas. São Paulo, n. 4, p. 317-342, 2000, p. 325-326).

${ }^{6}$ Ibid., p. 50. Grifos meus.

${ }^{7}$ RETÓRICA a Herênio. [Cícero]. Trad. e Intr. Ana Paula C. Faria e A. Seabra. São Paulo, 2005, Livro IV, [2]. Neste Livro, o autor (Cícero? Cornificius? Pseudocornificius?) escreve sobre a elocução e o correto uso dos exemplos.
} 
escolher diligentemente coisas várias e distintas, dispersas e espalhadas entre tantos poemas e discursos, para poder subordinar cada tipo de exemplo a cada tópico da arte ${ }^{8}$, para concluir, mais adiante: "Eis, portanto, a maior arte: poder também, em seu próprio tratado, fazer uso de exemplos alheios ${ }^{9}$ ". Creio que ambos os pontos de vista sejam algumas das raízes do gosto medieval pela glosa - o respeito à autoridade e a recorrência à erudição com fins estéticos. Ernst Robert Curtius, ao se referir às sentenças e aos exemplos difundidos na Antiguidade, remete a Clearco de Soles, da escola de Aristóteles. Nos banquetes, um verso ou uma sentença eram proferidos, e a mesma ideia deveria ser respondida por outro poeta. Nessa disputatio, "era preciso saber de cor versos de Homero, começados e terminados com a mesma letra, ou cujas primeiras e últimas sílabas, reunidas, formassem um nome, um utensílio ou uma iguaria $^{10}$." Parece-me que esse é um dos fatos que dará origem à disputatio medieval: a tensó $^{11}$, o partimen ou joc parti ${ }^{12}$, o tornejamen ${ }^{13}$, a cobla ${ }^{14}$ ou ainda a cobla tensonada ${ }^{15}$ provençais, além da "tenção"

\footnotetext{
${ }^{8}$ RETÓRICA, 2005, [1].

${ }^{9}$ Ibid., [3]. Grifos meus.

${ }^{10}$ CURTIUS, Ernst Robert. Literatura Europeia e Idade Média Latina. São Paulo: Ed. Hucitec, 1996, p. 95.

11 "La tensó (contentio, 'disputa') es un debate entre dos trovadores en el cual cada uno defiende lo que cree más justo, conveniente o está de acuerdo con sus preferencias" (RIQUER, Martín de. Los trovadores. Historia literaria y textos. Barcelona: Ed. Ariel, S. A., 2001, Tomos I, II e III. Colección Letras e Ideas, p. 67, vol. I). Joseph Ghamine López apresenta uma pequena distinção entre a tensó e o partimen: "Agora, a distinción que se fai entre un [tenção] e outro [partimen] xénero ten que ver coa maior ou menor ligazón entre os participantes no debate e as posturas que van defender, e non tanto con características formais do texto. (...) Máis ben se trataría de dous xeitos diferentes de afrontar o debate: no caso da tenzón, como disputa e no caso do partimén, como xogo dialéctico sobre asuntos relacionados co mundo trobadoresco". (LÓPEZ, Joseph Ghamine. A tenzón e o partimén: definición dos xéneros a partir das artes poéticas trobadorescas e dos propios textos. Madrygal. Revista de Estúdios Gallegos. Madri, v. 5, p. 61-72, 2002, p. 67).

12 "En el partimen o joc parti el trovador que torna la palabra plantea a su adversario un problema que puede tener dos soluciones y se compromete a defender la alternativa contraria a la que escoja su interlocutor". (RIQUEUR, op. cit., p. 67).

13 "Así como la 'justa' era el combate de un caballero contra otro y el 'torneo' el de varios caballeros contra varios, existe en literatura provenzal el tornejamen, poesía en la que debaten varios trovadores". (Ibid., p. 68).

${ }^{14}$ "La cobla es un debate breve, en una o dos estrofas, a veces con tornada, y es término que no debe confundirse con la denominación genérica de la estrofa que integra una composición larga ni con la cobla no dialogada, por lo general moralizadora, epigramática o satírica" (Ibid., p. 69). No CGGR, encontram-se vários exemplos de poemas assemelhados à cobla breve provençal ("ajudas", "perguntas" e "respostas" de duas estrofes).

15 "La que 'Las leys d'amors' (...) llaman cobla tensonada es una estrofa, o conjunto breve de estrofas, con tornada, en la cual los dialogantes intervienen en versos dentro de la misma estrofa". (Ibid., p. 69).

${ }^{16}$ A "tenção" é a versão galego-portuguesa do debate poético medieval derivada da tensó, do partimen ou joc parti, do tornejamen, da cobla e da cobla tensonada.
} 


\section{Revista Signum, 2014, vol. 15, n. 1.}

e respostas ${ }^{17}$ cultivadas pelos poetas quatrocentistas e quinhentistas castelhanos e portugueses. Mas também poderia ser a origem do gosto pela glosa, uma vez que o processo é o mesmo: incorporação de sentenças, exemplos, versos de autores, antigos ou não, aos poemas desenvolvidos pelo poeta medieval. Glosar, parece, é nada mais que isso: buscar referência nos autores antigos e emular as ideias e mesmo - no caso concreto da glosa - copiá-los. Em Los trovadores, Martín de Riquer parece referir-se à glosa quando relata que "los textos de los trovadores se comparan con pasajes bíblicos y patrísticos, que demuestran el gran conocimiento que tenían los poetas provenzales de la literatura sacra ${ }^{18}$." É assim que a glosa incorpora tanto elementos sacros como profanos.

Quanto ao apreço e veneração pelos autores vizinhos aos portugueses, Aida Fernanda Dias pensa

nas afirmações, sistematicamente repetidas, sobre a projeção de muitos textos da colectânea e na admiração e culto que os poetas do Cancioneiro votavam aos seus congêneres castelhanos, aspecto que sobressai de uma primeira leitura da obra e que leva, obrigatoriamente, a citar o galego Macías, Juan de Mena, o Marquês de Santillana, Juan Rodríguez del Padrón, Jorge Manrique, Stúñiga, Garcí Sanchez de Badajoz e, mais raramente, Aguilar. São estes, para os estudiosos do Cancioneiro, os poetas do reino vizinho que os colaboradores da colectânea de Resende admiravam e até veneravam ${ }^{19}$.

A autora ainda complementa:

se, para muitas poesias e versos soltos, abonados no Cancioneiro Geral, vamos encontrar os originais em diversos cancioneiros, quer tipicamente castelhanos, quer ligados por laços políticos ao reino vizinho, outros há que permanecem para nós verdadeiras incógnitas, enquanto mais afortunadamente, um que outro pode ser restituído à forma original e

17 "Em qualquer subgênero cancioneiril, como o vilancete ou a cantiga, por exemplo, há um mote, que é glosado (desenvolvido em versos) pelo proponente ou por outros poetas, dando surgimento às ajudas (quando a um outro poeta é solicitada sua opinião em relação a um questionamento feito pelo proponente), às perguntas (dúvidas propostas por um poeta em forma de pergunta, pedindo a outro que responda de acordo com sua sabedoria ou conhecimento sobre o lema) e às respostas (esclarecimentos da dúvida trazida no mote pelo poeta proponente)" (FERNANDES, Geraldo Augusto. Fernão da Silveira, poeta e coudel-mor: paradigma da inovação no Cancioneiro Geral de Garcia de Resende. 238p. Dissertação. [Literatura Portuguesa]. 2006. Faculdade de Filosofia, Letras e Ciências Sociais, Universidade de São Paulo, São Paulo, 2006, p. 69). Pierre Le Gentil considera esses "gêneros dialogados" uma forma avançada do paralelismo primitivo. (LE GENTIL, 1949, p. 597).

${ }^{18}$ RIQUER, 2001, p. 97, vol. 1.

19 DIAS, Aida Fernanda. O Cancioneiro Geral e a prosa peninsular de Quatrocentos. Contatos $e$ Sobrevivências. Coimbra: Livraria Almedina, 1978, p. 8. Cf. também MORÁN CABANAS, Maria Isabel. Mitificação de Macias o Namorado no Cancioneiro Geral de Garcia de Resende. In: Mitos (Actas del VII Congreso Internacional de la Asociación Española de Semiótica). Universidad de Zaragoza, Zaragoza, 1996, vol. III, p. 196. 
salvo da obliteração total, apenas porque alguns portugueses tiveram a feliz e oportuna ideia de os glosar (DIAS, 1978, p. 19)

Os poetas portugueses do Quinhentos ampliam, então, o culto à glosa ao trazer para seus textos não só a autoridade dos antigos, como também a de seus vizinhos.

Outra característica dos vilancetes, segundo Le Gentil, é que, como as cantigas e os villancicos, eles tinham formas musicais (melodia), e não eram para serem cantados, mas ditos. Havia uma clara separação entre música, agora polifônica, e poesia ${ }^{21}$. Massaud Moisés registra que a palavra "vilancete" vem do espanhol “"villancete', 'villano', vilão, habitante de vila, não fidalgo: cantiga de vilão, ou 'cantiga vilã', como registra a 'Arte de Trovar' que abre o CBN'”. A origem seria galego-portuguesa e o mote, muitas vezes anônimo, "denunciava a filiação tradicional, popular, do vilancete $^{22}$." A própria composição do vilancete aponta essa origem popular. É necessário registrar que Le Gentil não distingue "villancico" de "vilancete" e aplica as mesmas características para os dois casos. Já Massaud Moisés distingue um do outro: o vilancico teria sido introduzido em Espanha pelo Marquês de Santillana e

designava um tipo de canção popular correspondente, na sua estrutura, ao vilancete português: uma estrofe inicial, de dois a quatro versos (...), acompanhada de uma sequência de estrofes (...); cada volta compõe-se de três versos ou mais rimando entre si (constituem as mudanzas, na terminologia espanhola), um verso que rima com o estribilho (é a volta propriamente dita) e a repetição do estribilho: AA, bbbaAA, cccaAA, etc. ${ }^{23}$.

Percebem-se diferenças na estrutura e na maior liberdade de composição rimática e estrófica que os poetas portugueses aplicaram ao vilancete; já o vilancico segue maior rigor estrutural. Na prática, o que fazem os poetas do CGGR é marcar a diferença estrutural do vilancete em oposição ao vilancico.

Joaquín González Cuenca, editor do Cancionero General de Hernando del Castillo, informa que o villancico é um poema de forma fixa, composto, "en su versión más ortodoxa, por un estribillo inicial, llamado normalmente cabeza, y una o

\footnotetext{
${ }^{20}$ DIAS, 1978, p. 19. Contudo, pondera que "alguns motos devem ter sido criados cá [em Portugal] pelos nossos cortesãos, naquela tendência tão em voga de exercitar a pena nos dois idiomas peninsulares, em parte determinada pelo contato frequente entre cidadãos de Portugal e de Castela, por motivos de casamentos régios e respectivos séquitos e pelas terçarias de Moura". (Ibid., p. 20). Alan Deyermond alega que "la influencia castellana fue casi tan fuerte en esta época como en el período que abarca el Cancioneiro geral (c.1450-1516). La influencia se dio en todos los aspectos de la poesía: la versificación, los temas, el estilo, el género". (DEYERMOND, Alan. Poesía de cancionero del siglo XV: poetas palacianos. In: ___. Poesía de cancionero del siglo XV. [Valencia, ES]: 2007, p. 133-305, p. 153).

${ }_{21}^{21}$ LE GENTIL, 1952, p. 305-309.

${ }^{22}$ MOISÉS, Massaud. Dicionário de termos literários. São Paulo: Cultrix, 2004, p. 472.

${ }^{23}$ Ibid., p. 472. Grifo meu.
} 
varias estrofas, que, tras unos versos de mudanza, se rematan con la vuelta, que recoge más o menos modificados todos o al menos el último verso de la cabeza ${ }^{24}$." Informa ainda que, segundo Sanchez Romeralo, não se deve confundir o villancico culto, presente no Cancionero de Castillo, do popular, que, apesar de seguir a mesma estrutura métrica, "responde a otros principios de composición, sobre todo en el uso de una fraseología y una tópica peculiares ${ }^{25}$ ". No Cancioneiro de Resende, muitos vilancetes diferenciam-se do villancico pelo tratamento dado às glosas: nem sempre a modificação de um verso do mote é claramente observada nas glosas. Já António José Saraiva e Óscar Lopes apontam para o fato de que "esta forma, que tende para o comentário engenhoso de um dado tema, é especialmente adequada à mentalidade glosadora difundida pelos pregadores e pela Universidade, e, assim, presta-se admiravelmente ao gosto conceptista característico destes poetas palacianos ${ }^{26 "}$.

Eugenio Asensio, ao estudar o paralelismo, característica das cantigas trovadorescas, principalmente das cantigas de amigo, comenta que o vilancete, de certa forma, perpetuava o sistema paralelístico: "el villancico, con el retorno del estribillo, mantenía la técnica de replantear el mismo tema en cada estrofa, pero procuraba variar los términos, la distribución, las imágenes, con una libertad más amplia que el sentido semántico, para que la fórmula no ahogase la forma ${ }^{27 "}$.

Com relação ao número de versos por mote, apenas cinco vilancetes do $C G G R$ apresentam dísticos; os outros são todos tercetos. A maioria é composta de uma estrofe em sétimas, oitavas, nonas ou décimas. Ressalte-se que as estrofes que não sejam em sétimas fogem à "regra" da forma fixa própria do vilancete, pois sua definição clássica é ter estrofes de sete versos, haja vista os exemplares do próprio $C G G R$ e os de seu congênere, o $C G H C^{28}$. Sete vilancetes são em castelhano, um bilíngue (português/castelhano) e os restantes em português. Dez vilancetes apresentam pés quebrados, colocados em posições alternadas e não regulares; estes se alternam, também, entre trissílabos e tetrassílabos.

\footnotetext{
${ }^{24}$ CANCIONERO General de Hernando del Castillo. Ed. Joaquín González Cuenca. Madri: Ed. Castalia, 2004, Tomos I-V, p. 661, Tomo II.

${ }^{25}$ Ibid..

${ }^{26}$ SARAIVA, A. J. e LOPES, Óscar. História da Literatura Portuguesa. 16. ed. Porto: Porto Editora, Lda., [s.d.), p. 160-161.

${ }^{27}$ ASENCIO, Eugenio. Poética y realidad en el cancionero peninsular de la Edad Media. 2.ed. Madri: Ed. Gredos, 1970, p. 119.

${ }^{28}$ A partir de agora a sigla CGHC será a referência ao Cancionero General de Hernando del Castillo.
} 
Quanto à métrica, com exceção dos vilancetes 297 e 825, em redondilhos menores, todas as outras composições deste grupo apresentam-se em arte menor ${ }^{29}$. Em quatro poemas, os poetas não repetem o mote, desenvolvendo com outras palavras a ideia lançada; em alguns poemas, há repetição de apenas uma ou mais palavras ou mesmo de um ou mais versos do mote considerados "chave" no poema ${ }^{30}$. Os poetas palacianos costumavam glosar tanto motes quanto refrões, alheios ou não.

Há, ainda, outras características relevantes no $C G G R$, quanto à forma do vilancete e ao modo como os poetas a montaram. O vilancete 207 alterna estrofes em sétimas e oitavas, estas, na primeira e na última estrofe, registro da insistente irregularidade no Cancioneiro de Resende. O mesmo acontece com o vilancete 811: mote de três versos, duas estrofes de sete versos, mais uma (a do meio) com seis versos. Os vilancetes 709, 734 e 792 caracterizam-se por mote de dois versos e estrofes em quadras (seis no primeiro, quatro no segundo). Tal estrutura evidencia inovação dos poetas, uma vez que as glosas deveriam ser em sétimas. O poema 792 distingue-se dos outros dois por apresentar 42 estrofes em quadras, incluindo o fim, o que revela, novamente, inovação quanto à extensão do poema ${ }^{31}$. A didascália de Garcia de Resende data-o como do "ano de Cristo de mil quinhentos. XVI", ano em que foi publicado o Cancioneiro e revela, assim, a atualidade/releitura da forma "vilancete". O de no. 742 distingue-se dos demais por apresentar dois vilancetes. Inovam também ao colocar um "cabo" nos poemas 825 , 844 e 862 . Os vilancetes 839 e 862 fazem alusão a partitura musical escrita pelo próprio Garcia de Resende, um dos poucos poetas músicos do CGGR: 839, "Vilancete de Garcia de Resende, a que tambem fez o som"; 862: "Garcia de Resende, indo para Roma, veo a Malhorca com grandes tormentas e vio ũa gentil dama, que chamavam Dona Esperança e andava vestida de doo. E fez-lhe este vilancete e mandou-lho, entoado tambem per ele".

Quanto aos gêneros daqueles poemas que se puderam classificar, assim se mostram os vilancetes: dez de conselho, três de louvor, duas respostas, duas orações, dois de glosa/louvor, um de glosalanagrama, duas epístolas, uma pergunta, um de

\footnotetext{
${ }^{29}$ Nebrija define arte menor como "el dímetro yámbico, que los latinos llaman cuaternario, y nuestros poetas pie de arte menor, y algunos de arte real, regularmente tiene ocho sílabas y cuatro espondeos". (NEBRIJA, Antonio de. Gramática de la lengua castellana. Disponível em: <www.antoniodenebrija.org/indice.html>. [s.d.], L. II, Cap. VIII. Acesso em: 26.3.08.

${ }^{30}$ Massaud Moisés registra que "os versos do mote podem ser repetidos: um em cada estrofe, um só em todas, ou com variante que conserve a mesma palavra da rima, ao fim de cada estrofe". Isso permite que, nos critérios que montei, seja observada a incidência de uma palavra e de um ou mais versos considerados "chave" dentro da composição. (MOISÉS, 2004, p. 472).

${ }^{31}$ Essa inovação, colocar um fim ou cabo nos vilancetes, aparece também em outros vilancetes.
} 
pergunta/conselho, um diálogo, e, novidade, um longo poema épico em redondilho menor e estrofes em quadras (no. 792), o qual será analisado em seguida.

O tema do amor é recorrente também nos vilancetes: mais da metade desses poemas refere-se à temática amorosa. Trata-se ainda de um amor sofrido: o sentimento provoca desejo de morrer ${ }^{32}$, de matar-se; sofre-se pela perda do objeto amado; a beleza da dama e seu desprezo/maldade também são motivações e pena de sofrimento. Nesse conflito amoroso, a questão do bem, do contentamento e do prazer versus os males que o sentimento provoca é muito evidente; o desprezo da dama provoca desejo de vingança, fazendo emergirem enganos e desenganos, sentimentos de perdição etc. - tudo, enfim, desencadeia tristeza no poeta.

Um vilancete que destoa desse emaranhado de sofrimentos é o 687, em que o poeta se declara livre do amor que sentia pela dama, como se verá adiante. Em quatro vilancetes, o nome das amadas ou o lugar em que se encontra o poeta são motivos para brincadeiras poéticas ${ }^{33}$; vejam-se os vilancetes 26 (o poeta usa o sobrenome da amada - Guerra - e versifica o conflito em que vive por ela); 761 (o poeta, em Nossa Senhora da Pena, usa esse topônimo para cantar seu sofrimento de amor); 794 (o poeta toma um mote alheio, já vitorea nam é, e com ele, à moda do senhal provençal e galaico-português, esconde e versifica o nome da dama, Antonia Vieira) e o 862 (Garcia de Resende, amando uma dama chamada Esperança, diz o quanto sofre por não tê-la). Vilancetes jocosos ou satíricos são poucos, e isso talvez destoe da marca do $C G G R$, as cousas de folgar. Também se percebe certo preciosismo de tratamento nos vilancetes do último volume, bem mais numerosos. Ali estão presentes poetas que Jorge A. Osório identificou como da "nova geração"34.

\footnotetext{
${ }^{32}$ Aida Fernanda Dias comenta que esse topos ("viver-morrendo", em suas palavras) aparece inúmeras vezes, tornou-se clichê e atravessou séculos. Acredita que esse desejo pode estar ligado à história de Santa Teresa de Jesus. (DIAS, Aida Fernanda. Cancioneiro Geral de Garcia de Resende - A Temática. Maia: Imprensa Nacional - Casa da Moeda, 1998. Volume V, p. 297).

${ }^{33}$ Pierre Le Gentil denomina "etymologie" essas brincadeiras, e teria sido Villasandino um dos primeiros a recorrer a essa prática: "Il s'agit ici, essentiellement, de dégager la valeur symbolique des lettres qui composent un nom propre ou un prénom". (LE GENTIL, 1949, p. 190). Juan Casas Rigall denomina-as de locus a nomine. (CASAS RIGALL, Juan. Agudeza y retórica en la poesia amorosa de cancionero. Santiago de Compostela: Universidade, Servicio de Publicacións e Intercambio Científico, 1995, p. 164).

${ }^{34} \mathrm{O}$ autor dividiu o $C G G R$ em três blocos, cada um deles subdivididos por características diferenciadoras. Neste terceiro bloco, diz o investigador, "alguns poetas pertencem a uma geração mais nova: Jorge de Resende, Duarte de Resende, Gil Vicente, Bernardim Ribeiro" (OSÓRIO, Jorge A. Do Cancioneiro "ordenado e emendado" por Garcia de Resende. Revista da Faculdade de Letras, Línguas e Literaturas, Porto, Universidade do Porto, II série, v. XXII, p. 291-355, 2005, p. 307).
} 
Esses "novos" apresentam certa desconstrução no tratamento dos temas: num vilancete tradicional pela forma (687), Jorge de Resende declara não mais amar a "molher que servia". Garcia de Resende, na didascália, registra esse sentimento usando o verbo "desavir", que, entre outros sentidos, significa "malquistar". O mote apresenta três versos de esquema $\mathbf{A B B}$, com rimas masculinas no mote e nos dois últimos versos da glosa, como que marcando o regozijo de homem que venceu o amor; a glosa, em sétima, tem rimas misturadas em ababbcc, femininas nos cinco primeiros versos; o esquema é paralelístico, pois a sequência de rimas do mote é a mesma dos dois últimos versos da glosa. O poeta trabalha com as antíteses perder/ganhar no mote: a dama queria-o perdido, mas ele vence e regozija-se de se livrar dela. Eis o poema:

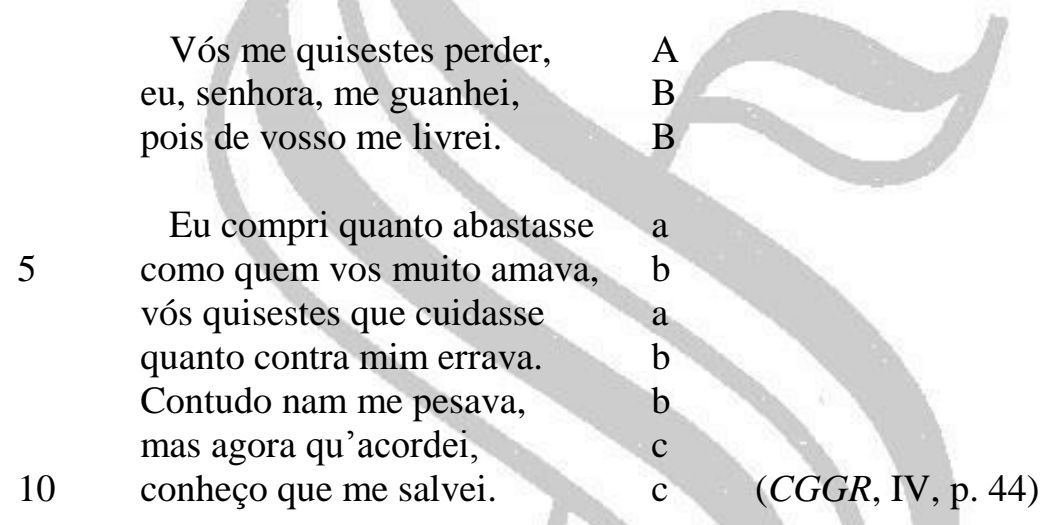

A dama continua sendo, neste vilancete, a dame sans merci, mas não é ela que vence reflexo dos novos tempos.

Marcadas pelos Descobrimentos, as novidades trouxeram a Portugal não somente riquezas e glória, mas também “desconcertos”. Os grandes feitos portugueses foram registrados nas mais diversas áreas de cultura, como se sabe, e eram motivo para versificação de temas que não apenas os das conquistas ultramarinas. Todo o ambiente de descoberta e conquista ultrapassa o fato econômico e histórico e mexe com os sentimentos: fatos gloriosos são comparados ao sentir do poeta em relação a qualquer atividade. Na temática amorosa não foi diferente: no vilancete 146, D. João Manuel dirige-se aos Cuidados e pede-lhes que o deixem, pois está longe de sentir prazer. Valendo-se de termos próprios da Navegação, o poeta sente-se prestes a “dobrar / o cabo de desventura". Diz aos cuidados: "nam vejo terra segura / onde me possa ancorar. / Pois me tam longe demora / sem ver porque me reger" e de tanto "a Fortuna correr / me fez (...) alijado" do descanso e do prazer, agora que só cuida da 
dor que sente e vai bradando - como se estivesse em uma nau conquistadora de terras impossíveis - pela senhora que ama e não o quer valer.

Se aqui o campo é a temática amorosa, em que o poeta recorre à terminologia própria das navegações, das conquistas, no vilancete a seguir a inovação está na forma e no gênero.

No longo vilancete 792 (42 estrofes em quadras, com mote de dois versos), Diogo Velho da Chancelaria metaforiza, pela annominatio, o substantivo "caça" e o verbo "caçar", relacionando-os às Conquistas dos portugueses. É inovador o poema, primeiro pela forma: um número muito grande de estrofes, versificadas em quadra e não em sétimas, como prescreve a forma do vilancete; também é inovador quanto ao gênero, pois é um poema épico, cuja metrificação esperada seriam os versos em arte maior, próprios para a exaltação e a erudição humanista. No entanto, como o texto permite duas leituras, o uso da arte real poderia justificar a métrica. O poema localiza-se no último volume da Coletânea e registra, na didascália, sua contemporaneidade: essa nova caça é "feita no ano de Cristo de mil / quinhentos. XVI.”, ou seja, no mesmo ano em que Garcia de Resende publicava seu Cancioneiro. O poema começa com um refrão ${ }^{35}$ em rimas emparelhadas $\mathbf{A A}$, altera-se para entrelaçadas - abba na segunda estrofe - e segue em monorrimas $\mathbf{a a a b}^{36} \mathrm{em}$ todas as outras. Note-se que as sílabas finais do grupo b são todas em “-al”, cuja desinência finaliza a palavra "Portugal", além de que, no mote, a rima dessa palavra é com "real": é evidente a intenção do poeta de ligar os feitos de sua pátria à realeza. Tanto é verdade que o nome dos monarcas aparece ao longo do vilancete, exaltados e comparados aos antigos, sobrevalorizados em relação aos antepassados - e aí pode estar a segunda leitura, a satírica, pontuada pela ironia. Leia-se o vilancete:

\footnotetext{
${ }^{35} \mathrm{O}$ refrão quatrocentista/quinhentista português não tem função de estribilho musical; ele é repetido no corpo do poema, mas integrado aos versos anteriores e posteriores. Quanto a ele, escreve Paul Zumthor: "Le terme de 'refrain' en effet, fréquent dans l'usage médieval, s'y réfère à la récurrence d'une coupure (frangere) plus qu'à la répétition de mots, comme nous l'entendons aujourd'hui ; par extension refrain peut désigner, de façon plus ou moins plaisante, toute chanson, comme notre mot retournelle". (ZUMTHOR, Paul. Le carrefour des rhétoriqueurs. Intertextualité et Rhétorique. Poétique, Paris, n. 27, p. 317-337, 1976, p. 246).

${ }^{36}$ António Feliciano Castilho vale-se desse mesmo poema para comentar a forma agradável do esquema rimático aaab: "Achamos também quadras, em que os três primeiros versos rimam entre si, e o quarto com o quarto da quadra seguinte". Em seguida, toma como exemplo o poema de Diogo Velho. (Cf. CASTILHO, António Feliciano. Tratado de metrificação portuguesa. Lisboa: Sociedade, 1908, p. 63).
} 
Revista Signum, 2014, vol. 15, n. 1.

Rifam.

Oh que caça tam real

A

que se caça em Portugal!

A

Rica caça, mui real, que nunca deve morrer, pera folgar de lhe correr tod'a jente natural!

a

b

Linda caça mui sobida a se descobre em nossa vida, a a qual nunca foi sabida nem seu preço quanto val!

oh da gram mata Lixboa, onde toda caça voa, Arabia, Persia e Goa, tudo cabe em seu curral! todos veem per ũu portal.

$\mathrm{a}$
$\mathrm{a}$
$\mathrm{a}$
$\mathrm{b}$

Talhamar da grã riqueza, a Damasco com forteleza, Troia, Cairo com sa grandeza a nom domarom nunca tal!

O mui sabio Salamom, a que fez o grande montom, a teve [sa] parte e quinhom, a mas nom todo o cabedal.

Mida, Anglia com norte e Alexandre tam forte nom conservou esta sorte nem o seu vidro cristal.

Priamo, Juba, Assueiro, a Membrot, Pompeo guerreiro, a nenhũ foi tam sobranceiro, a nem tam pouco Anibal. $\quad b$

35 Carina navegador a navegou com muita dor, a nunca foi descobridor a deste tam rico canal. $\quad b$ 
Hercoles, Cesar corredores a tambem foram caçadores a e nom foram achadores a deste cetro tam real.

Ciro, Porsena fronteiro, a Afrons, Jupiter herdeiro, a nenhũ foi tam verdadeiro a nem Saturno paternal. $\quad b$

Eneas, Ulixes caminheiro, a Tolomeu, Prinio messejeiro, a Nino, Remulo primeiro, a

50 jemerom, sabendo tal. b

Macabeu cos Doze Pares, a com seus deoses e altares, a nom teverom tais lugares a nem tal graça especial.

55 Ouro, aljofar, pedraria, gomas e especearia, toda outra drogaria se recolhe em Portugal.

\section{a} a

Onças, liõos, alifantes, b moonst[r]os e aves falantes, porcelanas, diamantes, é ja tudo mui jeral.

Jentes novas, escondidas, a que nunca foram sabidas, a sam a nós tam conhecidas a como qualquer natural.

Jacobitas, abassinos,

cataios, ultramarinos, buscam godos e latinos esta porta principal.

$\mathrm{O}$ avangelho de Cristo

75 Os das grandes carapuças, a longas pernas, grandes chuças, a fariseus, suas aguças, nem o Chinches austerial. b 
Revista Signum, 2014, vol. 15, n. 1.

Amaro e o Ermitam a em sua contemplaçom a leixarom revelaçom a deste horto terreal.

Em o ano de quinhentos a e com mil primeiro tentos a descobrirom os elementos esta caça tam real.

b

Em este segre cintel

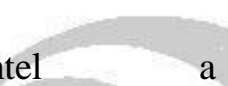
reina El-Rei Dom Manuel, que recolhe em seu anel sua devisa e seu sinal. a

Porque é mui virtuoso, excelente e justiçoso, Deos o fez tam poderoso rei de cetro imperial.

$\mathrm{a}$
$\mathrm{a}$
$\mathrm{a}$
$\mathrm{a}$
$\mathrm{a}$
b

Sua santa parçaria, Rainha Dona Maria, estas maravilhas lia por esprito divinal.

\section{a} a a b

Esta é jentil a andina pera cantar com a Mina, Çafim, Zamor, Almedina tambem é de Portugal!

Rezam é que nom nos fique a a alma do Ifante Anrique e que por ela se soprique ao nosso Deos celestrial,

a

Porque foi desejador e o primeiro achador d'ouro, servos e odor e da parte oriental.

O poderoso rei segundo Joham Perfeito, jocundo, que seguio este profundo caminho tam divinal,

\section{a} a

\section{O Cabo de Boa Esperança} descobrio com temperança por sinal e de mostrança deste bem que tanto val. 
Revista Signum, 2014, vol. 15, n. 1.

120

A madre consolador a

de muito bem sostedor, a

em virtudes fundador, a

sua parte tem igual, b

D'El-Rei Dom Joham parceira, a

Dona Lianor, herdeira a

125 natural e verdadeira a

rainha de Portugal. b

Emanuel sobrepojante, a

rei perfeito, roboante, a

sojugou mais por diante a

130 toda a parte oriental. b

Nunca sejam esquecidos, a seus nomes sempre sabidos a e de gloria compridos a pera sempre eternal.

135 Aquele grande prudente a profetizou do ponente e de toda sua jente caçar caça tam real. a a b

O gram Rei Dom Manuel a

140 a Jebusseu e Ismael tomaraa e fará fiel a lei toda universal. a

Ja os reis do Oriente a este Rei tam exelente pagam parias e presente a a seu estado triunfal.

Pola grande confiança a que em Deos tem e esperança a é-lhe dada gram possança a de memoria inmortal.

O dos mui lindos buscantes, a rasteiros e tam voantes caçadores rastejantes que caçam caça real, 
É o tempo achegado a pera Cristo seer louvado, a cada ũu tome cuidado a deste bem que tanto val. $\quad b$

As novas cousas presentes a sam a nós tam evidentes a 165 como nunca outras jentes a jamais virom mundo tal. $\quad b$

Fim.

É ja tudo descuberto, o mui lonje nos é perto, os vindoiros têm ja certo

O poeta inicia seu poema com uma annominatio: "caça", substantivo e "caça", verbo $^{37}$; essas palavras têm a função de enfatizar tanto os feitos das Descobertas quanto a de registrar que o velho costume da realeza de caçar animais foi alterado para um novo prazer, justamente o das conquistas ultramarinas. Seria essa mudança o mote para a sátira sutil do poeta? Na primeira estrofe, cujo esquema rimático é diferente de todas as outras, o poeta registra que tipo de caça caracteriza essa nova modalidade: sempre real, por isso não acabaria nunca. Na segunda, dá um preâmbulo do que será relatado em seguida: uma linda caça, muito extraordinária, nunca vista antes, e o que não tem preço deve ser cantado. Continua a exaltação, referindo-se primeiro às grandes cidades antigas, mas começando por Lisboa, metaforizada pela designação de "grande mata", "onde toda caça voa", desde aquelas da Arábia até as de Troia e Cairo (estrofes 3 a 5); nas estrofes 6 a 15, louvam-se os grandes homens, tanto os da Bíblia - Salomão, por exemplo -, os da Mitologia - Hércules, Eneias e Ulisses -, como também os grandes nomes históricos Alexandre, Pompeu, César, entre outros. Nas estrofes que seguem, relatam-se e exaltamse o que se conquistou: riquezas minerais (estrofe 16), animais (17) e humanas (18 e 19). Essa conquista de "cinco mil léguas" leva aos novos povos a verdade cristã - o “avangelho de Cristo" (estrofe 18) - até Chinches (Chincheo, na China) ${ }^{38}$, revelando todo o "horto terreal". Nas estrofes 22 a 31, homenageiam-se os grandes reis portugueses,

\footnotetext{
${ }^{37}$ LAUSBERG, Heinrich. Elementos de Retórica literária. Trad. R. M. Rosado Fernandes. Lisboa: Fundação Calouste Gulbenkian, 1966, p. 179. Casas Rigall classifica o procedimento como derivatio. CASAS RIGALL, 1995, p. 228-229.

${ }^{38}$ DIAS, Aida Fernanda. Cancioneiro Geral de Garcia de Resende - Dicionário (Comum, Onomástico e Toponímico). Maia: Imprensa Nacional - Casa da Moeda, 2003. Volume VI, p. 178-179.
} 
todos conquistadores - Dom Manuel, o Infante Dom Henrique, Dom João - e enaltecemse as esposas e mães desses fundadores do novo Portugal. No entanto, o grande louvado é Dom Manuel, que na estrofe 32 é chamado de Emanuel (Deus conosco) ${ }^{39}$, numa clara referência a Cristo, através de seu nome hebraico; os elogios ao rei seguem até a estrofe 37. Daí à conclusão, Diogo Velho incita os portugueses a tomar cuidado "deste bem que tanto val", pois as "jentes / jamais virom mundo tal", este que foi descoberto e que, pelos feitos da navegação, faz com que "o mui lonje nos é perto".

Apesar de exaltar as grandes conquistas portuguesas e o papel da realeza nesses feitos, algumas expressões soam irônicas, permitindo segunda leitura; o poeta estaria, na verdade, criticando o novo papel dos monarcas e a transformação de Lisboa em "mata", como diz na terceira estrofe da glosa, realçada pelo termo depreciativo "curral", onde tudo cabe. A nova modalidade de caça traz aos da realeza uma nova maneira de folgar, como atesta o poeta na segunda estrofe da glosa, e ninguém sabe o preço dessa folgança - "o preço quanto val” pode significar o valor material ou quanto custa (e custará) a Portugal a nova empreitada. Numa leitura literal, o encômio centra-se em Dom Manuel, que reina num mundo cintilante (segre cintel). ${ }^{40}$ No entanto, se se observar o excesso de atributos de louvação ao rei, percebe-se um fundo irônico - é o monarca "mui virtuoso, excelente e justiçoso, e tam poderoso" e, mais ainda: "sobrepojante, rei perfeito, roboante", que "a Jebusseu e Ismael / tomaraa e fará fiel / a lei toda universal". É o rei que "pola grande confiança / que em Deos tem e esperança / é-lhe dada gram possança / de memoria inmortal", ou seja, sobrepuja todos os antigos imperadores e reis da Antiguidade. Esses novos caçadores servem-se de "lindos buscantes", cães de busca ${ }^{41}$, rasteiros e voantes, que são também "lindos sabujos", cães de caça grossa ${ }^{42}$, e devem ser criados como "andujos", cães novos ${ }^{43}$, "pera casta natural”, podendo estar o poeta referindo-se àqueles de que se servem esses novos caçadores do Quinhentos português, a "jente natural". Nas estrofes finais, uma advertência, "cada ũu tome cuidado": deve-se tomar cuidado desses novos caçadores ou deve-se cuidar "deste bem que tanto val", que é a nova riqueza que aflora em Portugal?

\footnotetext{
${ }^{39}$ DIAS, 2003, p. 252. Observe-se, também, que o poeta valeu-se do nome em hebraico para que a métrica (o redondilho maior) do verso fosse perfeita.

${ }^{40}$ Ibid., p. 631; 183.

${ }^{41}$ Ibid., p. 139.

${ }^{42}$ Ibid., p. 616.

${ }^{43}$ Ibid., p. 71.
} 
Não há dúvida de que é um poema sobre as glórias de Portugal do Quinhentos; entretanto, a fina ironia, ressaltada pelo encômio hiperbólico, permite constatar que essas glórias estavam sendo conquistadas por um preço de que Portugal não poderia se orgulhar.

Ainda quanto a esses novos tempos, um vilancete especial deve ser citado: o de 825, de Francisco de Souza, que glosa o mote alheio: “Abaix'esta serra, / verei minha terra.". O singelo poema exalta a terra de que o poeta tem saudade. Num dos poucos textos em redondilho menor, Francisco de Souza registra a saudade dos montes, das ribeiras do mar, da serra, evidenciando estar longe de sua terra participando de uma guerra - aliás, a rima vai sempre girando em torno das três paronomásias: "serra" e “terra", obscurecidas pela "guerra". O cabo traz um verso em sétima em que a saudade é explícita, eivada de sentimento - até na força das palavras do esquema a:

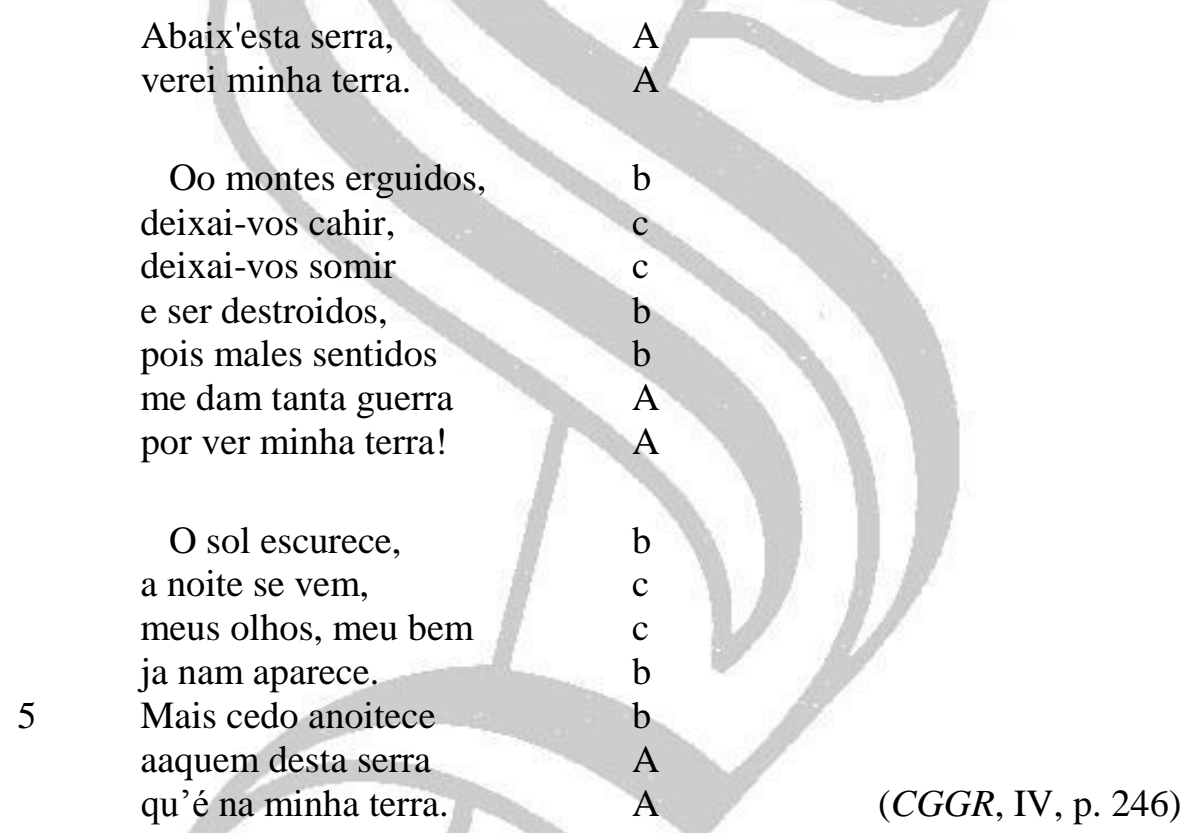

Mas o vilancete não aparece como peça isolada nos cancioneiros dos Quinhentos portugueses e castelhanos. Ele pode fazer parte de uma das composições mais originais e novidosas do período - os poemas que denomino de "formas mistas" de poemas do Cancioneiro Geral, estes são os que reúnem maiores novidades formais. Tendo por origem a sátira menipeia grega e romana e os “descordos” provençal e galegoportuguês, os poemas de formas mistas caracterizam-se pela mescla, numa só composição, de várias outras formas refletindo e resumindo a concepção de poetar dos compositores

\footnotetext{
${ }^{44}$ Em minha Tese de doutoramento, dedico um capítulo aos poemas de formas mistas e outro à retórica característica das composições do CGGR. Cf. FERNANDES, 2011.
} 
palacianos. Além da criatividade e originalidade, essa mistura de formas permitiu aos trovadores montarem um sistema de inovação e incorporação de temas e estruturas passadas numa só composição. O que se destaca nos 96 poemas mistos do $C G G R$ é que a maioria enquadra-se no gênero da disputatio, o que revela uma tradição literária de longa duração. Tradição que se deve levar em conta, pois, como diz Paul Zumthor, é a base da criação literária medieval, a qual, no entanto, não é monolítica - o que se revela nos poemas de formas mistas. Estes, diga-se de passagem, cultuam não só a tradição, mas, em consonância com as Leys d'Amors provençal, pretendem seguir a ordem da arte em vez da ordem da natureza - daí a criatividade e originalidade dos poetas palacianos.

Tomem-se como exemplos dois vilancetes que fazem parte de uma composição maior, mesclados a trovas. O primeiro - tirado de um longuíssimo poema composto de vinte e cinco trovas com estrofação irregular mais dois vilancetes - é o último que encerra as "Trovas que mandaram o Conde do Vimioso e Aires Telez à Senhora Dona Margarida de Sousa, sobre ũa perfia que tiveram perante ela, em que dezia Aires Telez que nam se podia querer grande bem sem desejar, e o Conde dezia o contrairo". Pela didascália, já se percebe o clima da disputatio revelado na palavra "perfia" e remete ao que Aristóteles e Quintiliano comentam sobre os entimemas compostos pelos contrários. Ao analisar um período, Lausberg refere-se à prótase e à apódose, em dois ou mais colos - sequência vocabular, constituída por mais de três palavras ${ }^{45}$. Casas Rigall comenta que a compositio periódica é a conformação sintática dos constituintes menores do discurso; nela a antítese é considerada sob a noção de período. As duas partes ou cola constituintes de um período são a prótase e apódose, que mantêm uma relação de tensão-distensão, cuja base é a antítese ${ }^{46}$. Numa perspectiva gramatical, há dois tipos de periodus - o enumerativo e o de membros sintaticamente interordenados; como há vínculos entre as partes, um depende do outro; seriam as coordenadas adversativas e as subordinadas adverbial, concessiva, condicional, causal e

\footnotetext{
45 “O período (periodus, ambitus, circuitus, períodos; port. período), como 'construção frásica cíclica (circular)' (oratio uincta atque contexta, connexa series, katestrammênê lexis), consiste na união de vários pensamentos (res) numa frase, de tal modo que seguidamente a um elemento (protasis; port. prótase), que cria tensão (pendens oratio), vem um elemento (apodosis; port. apódose), que dissolve a tensão (sententiae clausula)". (Cf. LAUSBERG, 1966, p. 258-266).

${ }^{46}$ Cf. CASAS RIGALL, 1995, p. 210.
} 
consecutiva $^{47}$. Todos esses elementos fazem parte da argumentatio - premissas e conclusões, argumentos e contra-argumentos ${ }^{48}$. Leia-se apenas o vilancete que encerra o poema de formas mistas no. 260:

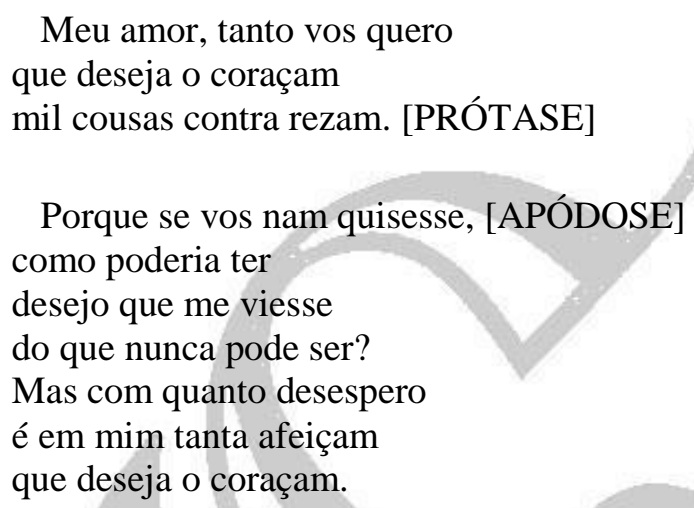

O poeta começa o vilancete com uma apóstrofe a coisas abstratas, e os contrários se revelam pela antítese "coração/razão" e pela amplificatio quantitativa. Quanto à compositio periódica, o mote é, então, a prótase. Segue-se a apódose, com suas características: o período argumentativo inicia-se pela conjunção "porque" e inclui, ainda, para que o argumento seja sutil, uma pergunta retórica (immutatio syntatica): “como poderia ter / desejo que me viesse / do que nunca pode ser?"; a conclusio é ainda mais aguda: começa por uma adversativa - mas -, e a immutatio syntatica se revela na exclamatio em que o poeta revela - também pelo processo da ratiocinatio - quão desesperado se encontra pelos desejos do coração.

No poema misto 572, um vilancete seguido de trovas com uma quadra por cabo do vilancete, na qual o Conde do Vimioso pede a ajuda dos colegas, o tema dos olhos em oposição ao coração e à razão é trabalhado, todo ele, por exempla, conselhos e alusões. Creio ser interessante ler-se o vilancete-mote da composição para que se observe a engenhosidade da construção do Conde, que resultará em trovas de ajuda não menos agudas e sutis - são 23 trovas compostas por 17 poetas que vêm colaborar com a proposição lançada no mote e no cabo do vilancete, em que o Conde conclama que, "se alguém for oprimido por seus olhos como eu sou (...) que acuda a este rifam.,"

\footnotetext{
${ }^{47}$ CASAS RIGALL, 1995, p. 211.

${ }^{48}$ Ibid., p. 214.

${ }^{49}$ Lembre-se que "rifam" tem também o sentido de mote.
} 
Revista Signum, 2014, vol. 15, n. 1.

Olhe bem no seu olhar quem quiser seguir rezam, qu'ee sinal do coraçam.

Nas cousas que daa vontade ela soo tem o poder, o engano é verdade, a rezam é o querer. Tudo vem a parecer honesto co a paixam senam o que é razam.

Sua.

Todo ver dos olhos vem, o olhar é com respeito, mil cousas parecem bem por querer, mas nam por jeito. E em concrusam do feito lá vam olhos e rezam onde vai o coraçam.

Sua.

Olhos haa pera culpar de cousas que nam tem cura, outros que com fermosura naceram pera matar.

Guai de quem haa-de passar ambas estas no serão, se nũs soos olhos estão!

Sua.

Se alguem for agravado dos seus olhos como sam, assi seja descansado qu'acuda a este rifam.

Aires Telez.

Nam tenho outro moor contrairo nem outro maior amigo, cos olhos ando em desvairo e eles nunca comigo. Que se me vem desejar de ver alguem no serão servem logo aa tenção. 
Sua.

Mas ũa cousa que folgo e me compre de calar nam posso dessimular qu'os olhos m'acusam logo. E entam vam-s'ajuntar com muito grand'afeição e sogigam na rezão.

Sua.

Mas façam no que quiserem, de tudo lhe dou perdam por enganos que me dam, quando ja mos dar nom querem. Pois quem haa-de desejar, nam tem d'outra salvaçam senam olhos d'afeiçam.

\section{Luis da Silveira.}

Nos olhos ha mil mofinas por onde rezam nom val, ja s'o mal é das mininas nam tomam nem dam sinal. Mas s'algũa embicar em olhar mal no serão eu l'ofereço ũ bordam.

Simão da Silveira.

A gentil dama benquista pera tudo bem fazer haa-se de perder de vista e porem guanhar no ver. $E$ a qu'isto nam souber e seguir openião traga-a alguem pola mão.

\section{Simão de Souza.}

A rezam é ja perdida, se s'o falar nam perdesse, ind'eu sei quem s'atrevesse achar mais males na vida. Mas o milhor é calar e provála concrusam co fruto qu'os olhos dam. 
Revista Signum, 2014, vol. 15, n. 1.

Vasco de Foes.

Quem for da minha idade mal vos pode responder, que pera saber e poder ja nam tem senam vontade. Quando al quero cuidar ou me parece rezam nam me deixa mais paixam.

\section{Dom Alvaro d'Abranches.}

Que meus olhos dêm cuidado, tenho-lh'o medo perdido, porqu'o mais fort'ee passado e sofrido.

Mas eu daqui me despedi, pera nunca com rezam afirmar minha tençam.

\section{Garcia de Resende.}

O primeiro movimento é dos olhos, quando vem, e se daa consentimento o coraçam é jaa bem. Isto é por mal de quem ha-de sofrer a paixam com rezam ou sem rezam.

Sua.

Tenho rezam sem na ter, tenho vida sem ter vida, tenho a paga recebida de meu mal soo polo ver. Ooh que ditoso perder, que grande satisfaçam é perda com tal rezam!

\section{Sua.}

Quem bem vir a deferença verá que digo bem nisto: que devo fazer pendença do que dantes tinha visto. Pois vós fostes causa disto, meus olhos, meu coraçam, sofrei, que tendes rezam. 
Revista Signum, 2014, vol. 15, n. 1.

Dom Gonçalo.

Se taqui olhei alguem, nam cuide ninguem qu'olhava senam soo quem me matava. Quem haa muito que me tem, quem é meu mal e meu bem, meus olhos, meu coraçam, cedo o descobriram.

\section{Manuel de Goios.}

Nos seus olhos, nos alheos, olhe cada ũ por si, neles vejo eu em mi o de qu'eles andam cheos. E pois meus olhos sam meos do fim de meu coraçam, os outros tambem no sam.

Joam Rodriguez de Saa.

Ainda que s'isto faça pera m'a mim soo matar, quem nam ha-de perdoar olhos de garça?

Estes nam s'acham na praça, mas vê-los-ês no serão, nunca postos em foam.

\section{Alvaro Fernandez} d'Almeida

A rezam é menos parte para s'homem ajudar dela, cada ũu pola su'arte, todos se perdem por ela. E pois o qu'eu tiro dela sam males sem concrusam, tire-me Deos a tençam.

\section{Diogo de Melo.}

Toda dor que traz cuidado, quem na bem sabe sentir mal a pode encobrir, se dela é jaa tomado. Nam deve de ser culpado nenhũ mal do coraçam, se lho fazem sem rezam. 
Revista Signum, 2014, vol. 15, n. 1.

Sua.

Este soo descanso tem minha vida sem ter al, sente tanto o qu'outrem tem quanto eu sinto [o] meu mal. Nesta vida hei-d'acabar, pois tomei a condiçam de quem faz a sem rezam.

\section{O Estribeiro-moor.}

Meus olhos me dam tal vida, quando meu mal faz mudança, qu'a razam nam daa saida onde falece esperança. Mas ja queria acabar e padecer a rezam a pena do coraçam.

Sua.

Vivi na fee do engano, o coraçam consentio, dos olhos me veio o dano, a rezam me descobrio. Nam quero meu mal cuidar, porque sinto tal paixam qu'hei gram med'oo coraçam.

Joam d'Abreu.

Qu'eu nam seja pera ver, tenho olhos com que vejo que nam pode ver prazer quem quer grande bem sobejo. Isto soube conhecer cos olhos do coraçam senhora, qu'est'ee foão.

Dom Joam de Me[ne]ses.

Ũs olhos andam aqui, que, olhando oo desdem, nunca passam por ninguem que nam levem após si. $E$ alguem cuida que ri, que traz ja no coraçam o nome de cujos sam. 
Sua.

Sem fazer bem nem mercê, olha sempre com tal jeito, que a torto ou a direito tudo leva quanto vê. Nam ha nela nenhũ sê e por maior perfeiçam ri-se muito da rezam.

\section{Gonçalo da Silva.}

\section{Fim.}

Meus olhos sam agravados da vida que têm tomada e nam podem ser curados senam com agua rosada, o que nam lh'aproveita nada, porque sam de tal feiçam que me dá muita paixam.

Restringindo a análise ao vilancete que abre a composição mista, percebe-se que no mote o Conde dá um conselho seguido de um exemplum composto por uma definitio - o coração é espelho da razão. Na primeira glosa, dois exemplos completam o pensamento lançado no mote, compostos, também, pela definitio: primeiro exemplum: "Nas cousas que daa vontade / ela soo tem o poder, / o engano é verdade, / a rezam é o querer". E no segundo: "Tudo vem a parecer / honesto co a paixam / senam o que é razam". Observe-se que o poeta vai jogando com as similaridades entre olhos, coração e razão - aqueles não seguem esta quando se trata de paixão. Num jogo em que entram annominatio, hipérbole, aliteração, inversio e antítese, o Conde constrói um silogismo, em que demonstra como a razão e o coração são submissos aos olhos, e esse sentido é explorado por todos os intervenientes, numa composição eivada de figuras e tropos.

Para Pierre Le Gentil, Andrée Crabbé Rocha, Jole Ruggieri e a mais recente estudiosa do $C G G R$, Aida Fernanda Dias, a forma é uma das características que mais marca a compilação de Garcia de Resende, aliada à irregularidade. No entanto, que forma é esta? A forma composicional é elemento básico da inovação quinhentista, pois, apesar de calcados na tradição, os poetas palacianos primaram por adaptar as formas originárias da Antiguidade ou da Alta Idade Média - e mesmo as contemporâneas a eles - a um novo 
contexto, que muitos estudiosos denominaram de Pré-Renascimento. Os vilancetes, assim como as cantigas, as baladas, as esparsas e as trovas, não deixaram de ter uma estrutura similar à de sua origem, mas adquiriram duas peculiaridades: a extensão no número de estrofes - muito maior que sua estrutura tradicional - e a incorporação de novos temas próprios do novo momento em que vivia Portugal do Quatrocentos e do Quinhentos.

Nos exemplos de vilancetes analisados neste estudo, nota-se, como em todas as outras cinco formas do Cancioneiro resendiano, que a procura central é a de inovação e adequação dos novos temas a formas já consagradas, no entanto, a extensão poemática é expandida e a essa forma relida são incorporados novos temas. Pertencentes aos poemas de formas fixas, essas composições caracterizam-se por trazerem um mote que depois será glosado - assim como a cantiga. Os vilancetes servem também como parte das ajudas, perguntas e respostas, quando incorporados aos "poemas de formas mistas", como visto nos exemplos trazidos neste estudo. Algo que chama a atenção, quanto aos vilancetes e às cantigas, nem sempre a glosa é o dobro de versos do mote, o que remete a outra característica marcante do CGGR: a irregularidade. Também, com o grande apreço pelos "pés quebrados", seu uso em quaisquer dos poemas do Cancioneiro permite constatar que a forma deve ser sempre relida e reestruturada sob um novo ângulo, apropriado a um momento novo por que passava a sociedade medieval em seu dealbar. 